\title{
A comparison of the aversiveness of denatonium saccharide and quinine in humans
}

\author{
STEPHEN F. DAVIS, CATHY A. GROVER, and CYNTHIA A. ERICKSON \\ Emporia State University, Emporia, Kansas
}

\begin{abstract}
One hundred and twenty undergraduate college students (60 males, 60 females) sampled and rated two bitters, denatonium saccharide and quinine. For each of three chemical concentrations $(1 / 1,000,1 / 5,000$, and $1 / 10,000)$, denatonium saccharide was rated as significantly more unpleasant than quinine by both males and females. These results, unlike those obtained with rat subjects, suggest the efficacy of adding denatonium saccharide to various toxic chemicals to deter human consumption.
\end{abstract}

In agreement with the contention that the newly discovered chemical denatonium saccharide (denatonium) is the most bitter substance currently available ("As Bitter," 1985), recent reports have shown that denatonium presentation significantly suppressed fluid intake in rats (Davis et al., 1986) and grasshopper mice (Langley, Theis, Davis, Richard, \& Grover, 1987). On the other hand, even more recent reports (Davis, Grover, Erickson, Miller, \& Bowman, 1987) directly comparing denatonium and the more common bitter quinine have demonstrated clearly that denatonium was consumed in significantly greater amounts. Furthermore, unlike quinine, denatonium was unable to support negative hedonic shifts when paired with neutral flavors. These results, in conjunction with data showing that the suppressive effects produced by denatonium may be transitory in nature (Davis et al., 1986), suggest that the initial claims of denatonium's excessive bitterness may have been exaggerated. However, it must be acknowledged that the results questioning the strength of denatonium's suppressive power came from studies in which rodents were used as subjects. The generalizability of such data to humans has yet to be demonstrated. The present experiment was designed to address this issue.

\section{METHOD}

\section{Subjects}

A total of 120 undergraduate college students (60 males, 60 females) enrolled in introductory psychology courses at a midwestern university volunteered to serve as subjects.

\section{Apparatus \\ The testing equipment consisted of six 1-cm high, 6-cm-diam circu- lar glass dishes and a supply of plastic toothpicks. Plastic toothpicks were employed in an attempt to avoid differential absorption that might have resulted from the use of wooden toothpicks. Separate toothpicks were used for the tasting of each fluid by each subject.}

Portions of this paper were presented at the 1987 meeting of the Southwestern Comparative Psychology Association, New Orleans, LA. Requests for reprints may be addressed to Stephen F. Davis, Department of Psychology, Emporia State University, Emporia, KS 66801-5087.

\section{Procedure}

Each subject was randomly assigned to one of six groups, each composed of 10 males and 10 females. Two of the six groups were randomly assigned to receive the 1 part chemical per 1,000 parts water concentrations, two were assigned to receive the 1 part per 5,000 parts concentrations, and two were assigned to receive the 1 part per 10,000 parts concentrations. One group within each of these concentrations received denatonium first, followed by quinine; the second group received quinine first, followed by denatonium.

Testing was conducted in two adjoining classrooms. All subjects reported, at preassigned intervals, to one classroom, where they read and signed an informed-consent document. At the designated experimental time, each subject individually was admitted to the second room and seated at a table. Two glass dishes containing the designated fluids for that subject were placed in front of the subject. Each dish was filled to within 2-3 mm from the top. To ensure that all subjects received similar exposure, each toothpick was dipped into the respective fluids and placed directly on the center of the subject's tongue by the experimenter.

After tasting each fluid, the subject was asked to rate the fluid's taste on an 11-point Likert scale that ranged from 1 (worst I've ever tasted) through 6 (neither pleasant nor unpleasant) to 11 (most pleasant I've ever tasted). A 10-sec interstimulus interval separated the tasting of the two fluids for each subject. During this interval the subject completed the rating of the first fluid tasted.

\section{RESULTS}

As preliminary analyses comparing males and females within each group failed to yield reliable differences, these data were pooled for the purposes of graphing and further analysis. Group mean denatonium and quinine ratings for the three fluid concentrations employed in this experiment are shown in Figure 1.

An analysis of variance performed on these ratings yielded significant effects for type of fluid (denatonium vs. quinine) $[F(1,114)=39.65, p<.001]$ and order of presentation (denatonium-quinine vs. quinine-denatonium) $[F(1,114)=5.65, p<.05]$.

\section{DISCUSSION}

Several points of interest emerge from a consideration of these data. First, it is obvious that the 120 subjects tested in this experiment were in agreement that, regardless of the concentration, denatonium was more unpleasant or aversive than quinine. This perception held true whether denatonium was tested before or after quinine exposure. However, the 


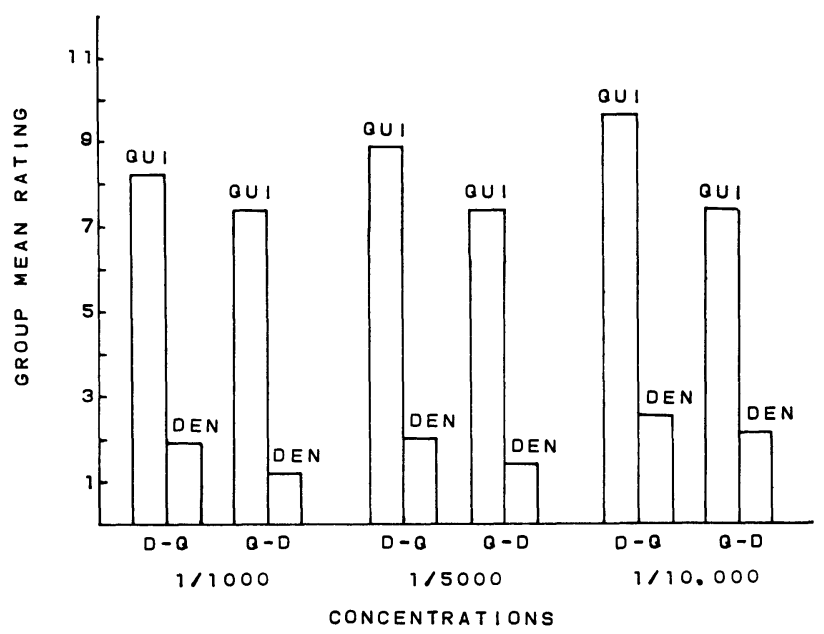

Figure 1. Group mean rating $(1=$ worst I've ever tasted; $11=$ most pleasant I've ever tasted) of denatonium and quinine as a function of concentration $(1 / 1,000,1 / 5,000$, and $1 / 10,000)$ and sequence of presentation (D-Q = denatonium followed by quinine; $Q-D=$ quinine followed by denatonium).

ratings for both fluids were lower when quinine was tasted first. This contrast indicates that when the subject tasted the less noxious fluid (i.e., quinine) first, with nothing to contrast it with, its rating was depressed. Subsequent exposure to the more noxious denatonium resulted in its being rated lower as well. If, however, denatonium was sampled first, both its rating and that of the second, less noxious, fluid were elevated.

Figure 1 also indicates that there was a trend for ratings of both fluids to increase as concentration decreased. This trend, however, failed to achieve statistical reliability.

Finally, a somewhat puzzling feature of these data, which may have some bearing upon the contrasts just discussed, must be addressed. It will be recalled that a rating of 6 was designated as neither pleasant nor unpleasant. Figure 1 clearly indicates that quinine was rated more toward the pleasant end of the scale. Surely our subjects did not perceive the taste of quinine, albeit weak, as a very pleasant gustatorial experience. A neutral response would have been more expected. It seems likely that the informed-consent form supplied to each subject prior to the test session may have biased the results. These forms indicated to the subject that he/she would "be tasting potentially bitter substances in this experiment." Hence, an expectation of a bitter taste may have been established prior to the actual test. In this context, the perception of the apparent lack of bitterness of the quinine may have been exaggerated. Likewise, the instructions on these forms may have enhanced the subjects' negative reaction to the denatonium saccharide.

Despite such speculation, it is clear that human subjects, unlike rats, find denatonium to be quite noxious, even in very dilute solutions. On the basis of these data, the addition of such compounds to toxic substances such as paint thinner, turpentine, and Drano (as proposed by, e.g., Berning, Griffith, \& Wild, 1982) to deter consumption by small children seems warranted and potentially effective.

\section{REFERENCES}

As bitter as they come. (1985). Science News, 123, 9.

Berning, C. K., Griffith, J. F., \& WiLD, J. E. (1982). Research on the effectiveness of denatonium benzoate as a deterrent to liquid detergent ingestion by children. Fundamentals of Applied Toxicology, 2, 44-48.

Davis, S. F., Cunningham, L. A., Burke, T. J., Richard, M. M., LANGLEY, W., \& THEIS, J. (1986). A preliminary analysis of the suppressive effects of denatonium saccharide. Bulletin of the Psychonomic Society, 24, 229-232.

Davis, S. F., Grover, C. A., Erickson, C. A., Miller, L. A., \& Bowman, J. A. (1987). Analyzing the aversiveness of denatonium saccharide and quinine in rats. Perceptual \& Motor Skills, 64, 1215-1222.

Langley, W. M., Theis, J., Davis, S. F., Richard, M. M., \& Grover, C. A. (1987). Effects of denatonium saccharide on the drinking behavior of the grasshopper mouse (Onychomys leucogaster). Bulletin of the Psychonomic Society, 25, 17-19.

(Manuscript received for publication May 1, 1987.) 